\title{
Resistência à Síndrome Ascítica, Competência Homeotérmica e Níveis de Hsp70 no Coração e Pulmão de Frangos de Corte ${ }^{1}$
}

\author{
Renata Hernandes ${ }^{2}$, Jesus Aparecido Ferro ${ }^{3}$, Elisabeth Gonzales ${ }^{4}$, Marcos Macari ${ }^{5}$, \\ Francisco Ernesto Moreno Bernal ${ }^{6}$, Maria Inês Tiraboschi Ferro ${ }^{7}$
}

RESUMO - Como em outros seres vivos, também nas células das aves ocorre a síntese das proteínas de baixo peso molecular (Hsp), cujo aumento é induzido sob condições de estresse. As Hsps têm um papel importante na manutenção da integridade celular, questionase o seu envolvimento no mecanismo de proteção celular de órgãos alvos na ocorrência da síndrome ascítica (SA). Este trabalho objetivou avaliar a temperatura corporal e os níveis da Hsp70 no coração e pulmão de frangos de corte Hubbard (sensível à SA) e caipira de pescoçopelado (resistente), criados em termoneutralidade $\left(25^{\circ} \mathrm{C}\right)$ e frio $\left(16^{\circ} \mathrm{C}\right)$ entre 10 e 45 dias de idade. Foram utilizados 192 pintos machos, 96 de cada linhagem. Não houve mortalidade por SA nas aves caipiras. Nas aves Hubbard, a mortalidade devida à SA foi de $4 \%$ e $41 \%$ em ambiente termoneutro e frio, respectivamente. Em ambiente frio, a temperatura corporal das aves Hubbard foi menor que a das caipiras. A temperatura corporal e o nível de Hsp70 do coração das aves Hubbard diminuíram com o aumento da idade, mas não nas aves caipiras, os quais se mantiveram constantes, inclusive a Hsp70 do pulmão. Independente da idade ou da temperatura, o nível de Hsp70 no pulmão das aves caipiras era superior ao das aves Hubbard. Em relação às aves Hubbard, as caipiras são homeotérmicas mais competentes e apresentam uma maior indução de Hsp70 nos órgãos primariamente afetados na SA, mas este não parece ser o sistema de proteção contra SA, a qual as aves de pescoço pelado são resistentes.

Palavras-chave: frango de corte, Hsp70, linhagem, síndrome ascítica, tolerância térmica

\section{Resistance to Ascites Syndrome, Homoeothermic Competence and Levels of Hsp70 in the Heart and Lung of Broilers}

\begin{abstract}
Similar to other living animals, the cells of the birds also synthesize small proteins (heat shock protein, Hsp), which increasing levels can be induce by stress. The Hsp have a relevant function in maintaining the integrity of the cell, and we question if they are involved in the mechanism of the cellular protection of target organs affected by ascites syndrome (AS). The objective of this study was to evaluate the body temperature, and the Hsp70 levels in the heart and lungs of broilers Hubbard (sensitive to AS) and nakedneck (resistant), raised under thermo-neutral (25C) or cold (16C) environments between 10 and 45 days of raising. We used 192 male chicks, 96 from each broiler strain. No AS mortality occurred among naked-neck birds, but $4 \%$ and $41 \%$ of Hubbard broilers submitted, respectively, to thermo-neutral and cold temperatures died due to AS. The body temperatures of cold-exposed-Hubbard-birds were lowers than that of naked-necks. The Hsp70 levels of heart and the body temperature of Hubbard chicks decreased as the age increased, for naked-neck these variables were constant during their lives, including the Hsp70 level in the lung cells. Independently from age or temperature effects, the lung cells of naked-neck birds had higher Hsp70 levels than those of Hubbard chickens. Comparing to Hubbard broilers, the naked-neck birds are more competent homoeothermics, and present superior level of Hsp70 in the organs firstly affected by AS, but it did not seem the system of protection against AS, in which the naked-neck birds are resistant.
\end{abstract}

Key Words: ascites syndrome, broilers, thermo-tolerance, Hsp70, strain

\section{Introdução}

Em todos os tecidos dos animais vivos são sintetizadas proteínas de baixo peso molecular que possuem funções específicas no crescimento celular e na reversão ou prevenção de danos causados por um estresse. Essas proteínas, cuja síntese é aumentada quando a célula é submetida a uma condição estressante, são denominadas proteína do choque térmico, heat shock protein ou Hsp, em inglês. Apesar de seu nome, vários outros fatores, além do calor, podem levar ao aumento da síntese das Hsp, tais como o frio, indutores de natureza

\footnotetext{
${ }_{1}^{1}$ Parte da dissertação de Mestrado do primeiro autor apresentada à UNESP/Jaboticabal, financiada pela FAPESP

2 Zootecnista. Doutoranda do Departamento de Zootecnia - UFV. CEP: 36571-000. E.mail: rehernan@bol.com.br

${ }^{3}$ Prof. do Departamento de Tecnologia da FCAVJ. E.mail:ferro@fcav.unesp.br

${ }^{4}$ Profa. do Departamento de Produção e Exploração Animal - UNESP/Botucatu. E.mail: elisa.gonzales@uol.com.br

5 Prof. do Departamento de Morfologia e Fisiologia Animal da FCAVJ. E.mail:macari@fcav.unesp.br

${ }^{6}$ Pós-graduando de Doutorado da FCAVJ.

${ }^{7}$ Profa. do Departamento de Tecnologia da FCAVJ. E.mail:mitferro@fcav.unesp.br
} 
química, física e biológica (metais pesados, inibidores do metabolismo, agentes quimioterápicos, febre, inflamação, infecções virais, isquemia), incluindo o ciclo de divisão celular e fatores de crescimento, que são mecanismos normais das células (Morimoto et al., 1994). As proteínas de estresse estão divididas em famílias, de acordo com seu peso molecular, sendo que as mais estudadas dessas proteínas têm pesos moleculares de aproximadamente 90,70 e $27 \mathrm{kDa}$ e, por isso, são denominadas, respectivamente, Hsp90, Hsp70 e Hsp27 (Guerriero \& Raynes, 1990).

Sabe-se que frangos de corte selecionados para altas taxas de crescimento e excelentes conversões alimentares e criados em altitudes não superiores a $2000 \mathrm{~m}$ acima do nível do mar apresentam altas taxas de morbidade e mortalidade devida à síndrome ascítica (SA). O rápido crescimento das aves e o ambiente frio são considerados os principais fatores predisponentes no desenvolvimento da SA (Wideman $\&$ Tackett, 2000). Linhagens de frangos de corte não selecionadas para rápido desenvolvimento, como as aves de pescoço pelado ( $\mathrm{NaNa}$ ou Nana), são resistentes à $\mathrm{SA}$, mesmo quando submetidas a condições que induzem a um aumento da incidência dessa patogenia em frangos de corte de alta produtividade (Gonzales et al., 1998).

O processo que mais freqüentemente leva os frangos a um quadro ascítico foi descrito por Julian (1987). Devido a uma insuficiente oxigenação, a taxa de batimento do coração aumenta na tentativa de suprir mais oxigênio para o rápido crescimento dos tecidos, causando uma hipertensão pulmonar. Com uma prolongada falta de oxigênio, o corpo aumenta a sua capacidade de carregar oxigênio no sangue pelo aumento do número de eritrócitos, o qual aumenta a viscosidade do sangue e agrava a hipertensão pulmonar. A crônica hipertensão resulta na hipertrofia do ventrículo direito e causa mau funcionamento da válvula átrio ventricular direita, que acaba permitindo o refluxo do sangue dentro da veia cava. Isso leva a congestão do fígado e o extravasamento de líquido para a cavidade abdominal. Quando a taxa de extravasamento é maior do que a capacidade das membranas abdominais em absorver o líquido, a ascite se desenvolve. Fica evidente, portanto, que os órgãos primariamente comprometidos no desenvolvimento do quadro ascítico são o pulmão e o coração.

O presente estudo objetivou testar a hipótese de que a proteína de estresse, ou de choque térmico
(Hsp70), está envolvida no mecanismo de proteção celular dos tecidos pulmonares e cardíacos em frangos de corte resistentes e suscetíveis à SA.

\section{Material e Métodos}

\section{Manejo das aves}

Inicialmente foram alojados 800 pintos machos de frango de corte, 400 da linhagem Hubbard e 400 caipiras de pescoço pelado (Nana), igualmente divididos em dois galpões climatizados, um termoneutro e outro frio. Dessas, 192 aves (96 Hubbard e 96 caipiras) foram utilizadas nas avaliações experimentais.

Nos primeiros cinco dias de criação, todas as aves foram mantidas em uma temperatura ambiente ao redor de $33^{\circ} \mathrm{C}$, termoneutra para a idade. Após esse período, no galpão denominado termo-neutro, as aves foram submetidas a um decréscimo de temperatura de aproximadamente $5{ }^{\circ} \mathrm{C}$ por semana, até atingir $24^{\circ} \mathrm{C}$, a qual foi mantida até os 45 dias de criação. No galpão frio, entre o sexto e décimo dia de criação, as aves foram submetidas a um decréscimo de temperatura de $3,5^{\circ} \mathrm{C}$ por dia, atingindo $16^{\circ} \mathrm{C}$ no décimo primeiro dia, mantendo-a até o final do período experimental.

Durante todo o período de criação, todas as aves receberam água e ração ad libitum. A ração foi fornecida na forma peletizada e continha $3200 \mathrm{kcal} / \mathrm{kg}$ de EMA e 22 e $20 \%$ de proteína bruta, nas fases inicial (1-21 dias) e final (22-45 dias), respectivamente. As rações experimentais foram formuladas para atender as exigências nutricionais sugeridas pelo NRC (1994).

Aos 14, 28 e 45 dias de idade, duas aves de cada repetição foram retiradas aleatoriamente para a mensuração da temperatura do cólon, sendo posteriormente sacrificadas para a coleta dos tecidos do coração e pulmão, usados na determinação da Hsp70. A temperatura retal foi medida utilizando-se um teletermômetro (Yellow Sprins Instruments, modelo 46TUC) acoplado a uma sonda retal (YSI n. ${ }^{\circ} 702$ ).

A mortalidade das aves foi registrada diariamente e as aves mortas foram necropsiadas para diferenciação da mortalidade por SA de outras causas. Líquido ascítico na cavidade abdominal, congestão generalizada, fígado e baço de aspectos anormais, aumento de volume cardíaco com hipertrofia ventricular direita e aspecto débil da ave com anexos desidratados são características que foram consideradas no diagnóstico da morte por SA. 
Determinação da proteína total e eletroforese

As amostras do tecido do pulmão e coração foram preparadas a partir da homogeneização de $0,5 \mathrm{~g}$ de amostra em $5 \mathrm{~mL}$ de tampão de lise $(20 \mathrm{mM}$ Tris-HCl, pH 7,5, 0,9\% $\mathrm{NaCl}$ e $2 \mathrm{mM}$ bmercaptoetanol), utilizando-se homogeneizador ultra-turrax, com velocidade de $20.000 \mathrm{rpm}$, em três vezes de 30 segundos e com intervalos de 30 segundos no gelo. O lisado total foi centrifugado a $16.000 \mathrm{rpm}$ por $30^{\prime}$ a $4^{\circ} \mathrm{C}$, em centrífuga Hitachi, CR 20B2, utilizando-se rotor RPR 20-2 ( $\left.\mathrm{n}^{\mathrm{0}} 7\right)$. O sobrenadante foi transferido para tubo de polipropileno de $15 \mathrm{~mL}$ e homogeneizado em homogeneizador de tecido tipo potter-Elvehjem (10 vezes). Duas alíquotas de $300 \mathrm{~mL}$ da amostra foram colocadas em microtubos, sendo que uma delas foi utilizada para eletroforese em gel de poliacrilamida (SDS-PAGE) e outra para a dosagem de proteína. Na alíquota para SDS-PAGE foi adicionado $100 \mathrm{~mL}$ de tampão de amostra para eletroforese $4 \mathrm{x}$ concentrado $(250 \mathrm{mM}$ Tris-HCl, pH 6,$8 ; 40 \%$ glicerol; $8 \%$ dodecil sulfato de sódio (SDS); 0,004\% azul de bromofenol) e $40 \mathrm{~mL}$ de b- mercaptoetanol. As amostras foram fervidas por 2', centrifugadas em microcentrífuga tipo Eppendorf e estocadas a $-20^{\circ} \mathrm{C}$ para análise posterior das proteínas em gel de poliacrilamida. $\mathrm{O}$ tubo contendo o precipitado foi desprezado.

A quantidade de proteína total presente no sobrenadante foi determinada pelo método de Hartree (1972), utilizando-se a soroalbumina bovina como padrão.

Para elaborar a reta-padrão foi utilizada a soroalbumina bovina ( $1 \mathrm{mg} / \mathrm{mL}$ - Sigma) em quantidades correspondentes a $0,20,40,60,80$ e $100 \mathrm{mg}$, analisadas em triplicatas.

As proteínas foram separadas por eletroforese em gel de poliacrilamida com SDS-PAGE, utilizando o método proposto por Laemmli (1970), sendo aplicado uma concentração de $15 \mathrm{mg}$ de proteína total por amostra de coração e pulmão. Utilizou-se o sistema de eletroforese da Bio-Rad (Mini-Protean II), com voltagem constante de $200 \mathrm{~V}$. Antes de serem aplicadas no gel, as amostras congeladas a $-20^{\circ} \mathrm{C}$ foram fervidas por $2^{\prime}$. Uma amostra de sobrenadante das aves Hubbard criadas em termoneutralidade serviu de referência, sendo aplicada em todos os géis. Também, um padrão de peso molecular (Gibco-BRL) foi usado em todos os géis.

R. Bras. Zootec., v.31, n.3, p.1442-1450, 2002 (suplemento)

\section{Técnica de Western Blotting}

A técnica de transferência das proteínas do gel para um suporte fixo (membrana) foi realizada de acordo com o método descrito por Towbin et al. (1979) e Matsudaira (1987). Após a eletroforese, o gel de poliacrilamida foi colocado em tampão de transferência (10 mM CAPS, $10 \%$ metanol) por pelo menos $5^{\prime}$. A transferência foi realizada a $90 \mathrm{~V}$ e $4^{\circ} \mathrm{C}$ por 40', utilizando-se o "Blotting apparatus" (Bio-Rad). A membrana foi corada utilizando-se Ponceau $\mathrm{S}$ $0,5 \%$ em ácido acético $1 \%$, e o gel corado com Coomassie Brilliant Blue, utilizando o método proposto por Morrissey (1981) para verificar a eficiência da transferência. Em seguida, a membrana foi lavada várias vezes com água deionizada.

As interações não-específicas foram bloqueadas usando $10 \mathrm{~mL}$ de TBS-leite gelada $(10 \mathrm{mM}$ Tris-HCl pH 8,0; $150 \mathrm{mM} \mathrm{NaCl}$; leite em pó desnatado $5 \%$ ) e Tween-20 em concentração $0,02 \%$ por uma hora a temperatura ambiente, sob agitação constante em agitador orbital (100 rpm, aproximadamente). Após este período, a membrana foi incubada com o anticorpo monoclonal anti-Hsp70 (Sigma H-5147) utilizando-se uma diluição 1:100 em tampão TBS-leite e Tween-20 em concentração $0,02 \%$, nas mesmas condições. Em seguida, procedeu-se a quatro lavagens da membrana com tampão TBSTween $(10 \mathrm{mM}$ Tris-HCl pH 8,0; $150 \mathrm{mM} \mathrm{NaCl}$; $0,05 \%$ Tween-20) por 5 'cada, e uma lavagem com tampão TBS (10 mM Tris- $\mathrm{HCl}$ pH 8,0; $150 \mathrm{mM}$ $\mathrm{NaCl})$ por 10 ', sob agitação constante. A membrana foi incubada com tampão TBS-leite $5 \%$ contendo o anticorpo secundário anti IgG de camundongo conjugado à fosfatase alcalina (Sigma A-5153) em uma diluição $1: 5000$, por $1 \mathrm{~h}$ a $25^{\circ} \mathrm{C}$, sob agitação. Após este período, novamente procedeu-se a lavagem da membrana, como descrito anteriormente. Sendo, então, desenvolvida a reação de cor com os substratos específicos da fosfatase alcalina, NBT ("nitro-blue tetrazolium chloride", $50 \mathrm{mg} / \mathrm{mL}$ em dimetilformamida $100 \%$ ) e BCIP ( 5 bromo-4cloro3 indolilfosfato $\mathrm{p}$-toluidina, $50 \mathrm{mg} / \mathrm{mL}$ em dimetilformamida 70\%), em tampão AP (100mM Tris-HCl pH 9,5; $100 \mathrm{mM} \mathrm{NaCl} ; 10 \mathrm{mM} \mathrm{MgCl} 2$ ), até visualização da banda correspondente à proteína Hsp70 (aproximadamente 2'). A reação de cor foi interrompida pela adição de solução de ácido tricloroacético 3\%. Após lavagem com água deionizada, a membrana foi seca à temperatura ambiente e ao abrigo da luz. 
O sinal de cor das bandas correspondentes à Hsp70 foi quantificado em densitômetro Shimdzu CS-9301, no módulo de reflectância e em "zig-zag", utilizando-se comprimento de onda de $525 \mathrm{~nm}$.

Quantificação da Hsp 70

Para quantificação da Hsp utilizou-se o método proposto por Givisiez (1997), no qual a proteína de choque térmico pura (Hsp70 - Sigma H-9776) foi reconstituída em glicerol $30 \%$, em uma concentração final de $0,05 \mathrm{ng} / \mathrm{mL}$. Alíquotas contendo 50, 100, 200, $300,350,400$ e $450 \mathrm{ng}$ de proteína foram preparadas e aplicadas em gel de eletroforese, assim como a amostra de referência em triplicata. Depois da eletroforese, a técnica de Western blot foi aplicada. As bandas foram analisadas no densitômetro. O valor médio obtido da quantidade de Hsp presente na amostra de referência foi utilizado para determinação da quantidade de Hsp das amostras das aves, através do cálculo da relação de área (área da amostra/área da amostra de referência). Para o cálculo da equação da reta utilizou-se uma média de três retas. Os valores obtidos foram convertidos em ng de Hsp70/mg de proteína total.

\section{Análise estatística}

Para avaliação da temperatura do cólon das aves e do nível de Hsp foi utilizado o delineamento inteiramente casualizado, em um esquema de parcelas subdivididas, com quatro tratamentos principais, em um esquema fatorial $2 \times 2$ (duas linhagens e duas temperaturas), e três tratamentos secundários (idades), com oito repetições de uma ave cada. Antes da análise de variância, o percentual de mortalidade foi transformado em arcoseno* $(\%+0,50 / 100) 0,5$. Na análise estatística dos dados foi utilizado o procedimento GLM do programa computacional estatístico SAS (1987).

\section{Resultados e Discussão}

\section{Desempenho produtivo e mortalidade}

Ao final dos 45 dias de criação as aves de pescoço pelado ou Hubbard criadas em ambiente termoneutro apresentaram desempenho produtivo compatível com a idade (Tabela 1). Entretanto, verificou-se que a criação em ambiente frio preju-

Tabela 1 - Desempenho produtivo e mortalidade dos frangos de 1 a 45 dias de idade criados sob condições ambientais de termoneutralidade $\left(25^{\circ} \mathrm{C}\right)$ e frio $\left(16^{\circ} \mathrm{C}\right)$

Table 1 - Performance and mortality of broilers from 1 to 45 days of age raised under thermo-neutral $\left(25^{\circ} \mathrm{C}\right)$ and cold $\left(16^{\circ} \mathrm{C}\right)$ environments

\begin{tabular}{|c|c|c|c|}
\hline \multirow[b]{2}{*}{$\begin{array}{l}\text { Variável }^{1} \\
\text { Variate }\end{array}$} & \multirow[t]{2}{*}{$\begin{array}{l}\text { Temperatura ambiental } \\
\text { Environmental temperature }\end{array}$} & \multicolumn{2}{|c|}{$\begin{array}{l}\text { Linhagem } \\
\text { Strain }\end{array}$} \\
\hline & & $\begin{array}{l}\text { Pescoço pelado } \\
\text { Naked neck }\end{array}$ & Hubbard \\
\hline Ganho de peso, $g$ & Termoneutra & $1268 \pm 28,7^{\mathrm{bA}}$ & $2113 \pm 72,3^{\mathrm{aA}}$ \\
\hline Weightgain & $\begin{array}{c}\text { Thermo-neutral } \\
\text { Fria } \\
\text { Cold }\end{array}$ & $1266 \pm 44,3^{\mathrm{bA}}$ & $1515 \pm 11,1^{\mathrm{aB}}$ \\
\hline Conversão alimentar & Termoneutra & $2,03 \pm 0,01^{\mathrm{aB}}$ & $1,83 \pm 0,03^{\mathrm{bB}}$ \\
\hline Feed ratio & $\begin{array}{c}\text { Thermo-neutral } \\
\text { Fria } \\
\text { Cold }\end{array}$ & $2,27 \pm 0,03^{\mathrm{bA}}$ & $2,39 \pm 0,12^{\mathrm{aA}}$ \\
\hline $\begin{array}{l}\text { Mortalidade } \\
\text { Mortality }\end{array}$ & & & \\
\hline Total, $\%$ & $\begin{array}{c}\text { Termoneutra } \\
\text { Thermo-neutral } \\
\text { Fria } \\
\text { Cold }\end{array}$ & $\begin{array}{l}4,05 \pm 0,00^{\mathrm{bA}} \\
6,17 \pm 4,25^{\mathrm{bA}}\end{array}$ & $\begin{array}{l}18,46 \pm 5,04^{\mathrm{aB}} \\
45,86 \pm 4,74^{\mathrm{aA}}\end{array}$ \\
\hline $\mathrm{SA}, \%$ & Termoneutra & $4,05 \pm 0,00^{\mathrm{aA}}$ & $8,15 \pm 4,73^{\mathrm{aB}}$ \\
\hline Ascites syndrome & $\begin{array}{c}\text { Thermo-neutral } \\
\text { Fria } \\
\text { Cold }\end{array}$ & $4,05 \pm 0,00^{\mathrm{bA}}$ & $37,65 \pm 6,18^{\mathrm{aA}}$ \\
\hline
\end{tabular}

R. Bras. Zootec., v.31, n.3, p.1442-1450, 2002 (suplemento) 
dicou o desempenho produtivo das aves, principalmente as Hubbard, que provavelmente já começavam a apresentar início de SA. A interação temperatura $\mathrm{x}$ linhagem significativa $(\mathrm{P}<0,50)$ revelou que as aves Hubbard apresentaram menor ganho de peso e pior conversão do que as suas contraparentes criadas em termoneutralidade. Por outro lado, somente a conversão alimentar das aves de pescoço pelado foi prejudicada $(\mathrm{P}<0,05)$ quando as aves foram submetidas ao frio, mas não o ganho de peso, o qual foi similar $(\mathrm{P}>0,05)$ entre as aves de pescoço pelado criadas em ambientes termoneutro e frio.

Observou-se que, no grupo de aves caipiras de pescoço pelado submetido a temperatura fria, a taxa de mortalidade foi de $2 \%$, mas nenhuma ave morta tinha ascite ou sinais que indicassem como causa morte a SA (Tabela 1). Entre as aves caipiras de pescoço pelado criadas sob termoneutralidade não houve mortes. Para as aves Hubbard, o ambiente frio determinou um aumento expressivo $(\mathrm{P}<0,05)$ de mortalidade total $\mathrm{e}$, principalmente, devida à $\mathrm{SA}(\mathrm{P}<0,05)$. Do total das mortes ocorridas entre as aves Hubbard criadas em termoneutralidade, $33 \%$ foi por SA. Em condições de criação em ambiente frio a maioria das aves Hubbard (75\% do total das mortes) morreu em conseqüência da SA.

Altas taxas de mortalidade devido à SA, como aqui observadas, já foram registradas na literatura para frangos de corte machos de alta produtividade, criados sob condições de temperatura fria e alimentados com rações peletizadas e de alta densidade nutricional (Gonzales et al., 1998a, b; Julian, 2000). À semelhança do observado por Gonzales et al. (1998b), neste estudo nenhuma ave de pescoço pelado morreu por SA, mesmo quando submetidas às mesmas condições ambientais das aves altamente produtivas, confirmando a resistência dos frangos de pescoço pelado à $\mathrm{SA}$.

A principal explicação fisiopatológica para a alta ocorrência de SA em aves geneticamente selecionadas para excelente desempenho é a sua alta demanda de oxigênio, principalmente os machos, quando criados sob condições de meio-ambiente predisponentes ao desenvolvimento do quadro ascítico, como o frio e o uso de dietas peletizadas de alta densidade nutricional. Para essas aves altamente produtivas, as exigências de oxigênio são tão grandes a ponto de desencadear um processo de anóxia tecidual e, por conseqüência, a SA (Macari et al., 1994; Julian, 2000).

R. Bras. Zootec., v.31, n.3, p.1442-1450, 2002 (suplemento)
Temperatura medida na região do cólon das aves

Houve efeito significativo $(\mathrm{P}<0,05)$ da interação linhagem e temperatura sobre a temperatura corporal medida no cólon das aves. O desdobramento dessa interação (Tabela 2) revelou que as aves Hubbard criadas em ambiente frio apresentaram um menor valor de temperatura corporal, tanto em relação às aves caipira de pescoço pelado, quanto em relação às próprias aves Hubbard criadas sob termoneutralidade, indicando que as aves caipiras são homeotérmicas mais competentes do que os frangos selecionados para alta taxa de crescimento.

As análises das interações linhagem $\mathrm{x}$ idade e temperatura $\mathrm{x}$ idade (Tabela 2 ) também foram estatisticamente significativas $(\mathrm{P}<0,05)$ e confirmaram a melhor tolerância das aves caipiras a ambientes frios até $16^{\circ} \mathrm{C}$. Os resultados mostraram que as aves caipiras mantiveram constantes as temperaturas corporais medidas aos 14,28 e 45 dias de idade, enquanto que as Hubbard apresentaram, em média, temperaturas corporais menores aos 28 e 45 dias, em relação aos 14 dias e em relação às aves caipiras. Esse efeito depressor da temperatura corporal das aves Hubbard criadas sob condições de frio refletiu sobre os resultados médios das temperaturas corporais em função da temperatura e da idade, independente da linhagem. Assim, em condições termoneutras, as aves mantiveram constantes as suas temperaturas corporais aos 14, 28 e 45 dias de idade. Em condições de criação de $16^{\circ} \mathrm{C}$, as temperaturas corporais foram menores aos 28 e 45 dias, sendo também diferentes entre si. Dentro de idades, o ambiente frio determinou menores temperaturas corporais das aves aos 28 e 45 dias de criação, mas não aos 14 dias de idade.

A mais eficiente capacidade homeotérmica das aves de pescoço pelado, quando colocada em condições de temperatura consideradas estressantes, foi plenamente demonstrada neste estudo. Outros autores já haviam demonstrado que essas aves são capazes de manter a temperatura corporal dentro de limites considerados normais, mesmo quando submetidas a altas temperaturas ambientais por um período prolongado (Mazzi, 1998; Yahav et al., 1998). Neste experimento, as aves de pescoço pelado mantiveram a sua temperatura corporal constante até os 45 dias de idade, em condições de temperaturas consideradas muito fria $\left(16^{\circ} \mathrm{C}\right)$ e por um período prolongado (35 dias). O mesmo não ocorreu com os frangos Hubbard, cujas temperaturas corporais foram significativamente deprimidas em condições ambientais 
Tabela 2 - Comparação de médias da temperatura corporal, em ${ }^{\circ} \mathrm{C}$, medida no cólon das aves dentro da interação linhagem $X$ temperatura ambiental, linhagem $X$ idade e temperatura ambiental $X$ idade

Table 2 - Body temperature average comparison $\left({ }^{\circ} \mathrm{C}\right)$ measured at colon, for environmental temperature $X$ broiler, broiler $X$ age, and environmental temperature $X$ age interactions

\begin{tabular}{|c|c|c|c|}
\hline \multirow[b]{2}{*}{$\begin{array}{l}\text { Linhagem } \\
\text { Strain }\end{array}$} & \multicolumn{3}{|c|}{$\begin{array}{c}\text { Temperatura ambiental }^{1} \\
\text { Environmental temperature }^{1}\end{array}$} \\
\hline & $\begin{array}{c}\text { Termoneutra }\left(25^{\circ} \mathrm{C}\right) \\
\text { Thermo-neutral }\end{array}$ & & $\begin{array}{c}\text { Fria }\left(16^{\circ} \mathrm{C}\right) \\
\text { Cold }\end{array}$ \\
\hline $\begin{array}{l}\text { Pescoço pelado } \\
\text { Naked neck } \\
\text { Hubbard }\end{array}$ & $\begin{array}{l}41,15 \pm 0,54^{\mathrm{aA}} \\
41,21 \pm 0,45^{\mathrm{aA}}\end{array}$ & & $\begin{array}{l}41,21 \pm 0,36^{\mathrm{aA}} \\
38,55 \pm 2,61^{\mathrm{bB}}\end{array}$ \\
\hline & \multicolumn{3}{|c|}{$\begin{array}{l}\text { Idade } \\
\text { Age }\end{array}$} \\
\hline $\begin{array}{l}\text { Linhagem } \\
\text { Strain }\end{array}$ & $\begin{array}{l}14 \text { dias } \\
\text { days }\end{array}$ & $\begin{array}{l}28 \text { dias } \\
\text { days }\end{array}$ & $\begin{array}{l}45 \text { dias } \\
\text { days }\end{array}$ \\
\hline $\begin{array}{l}\text { Pescoço pelado } \\
\text { Naked neck } \\
\text { Hubbard }\end{array}$ & $\begin{array}{l}41,34 \pm 0,21^{\mathrm{aA}} \\
41,13 \pm 0,37^{\mathrm{aA}}\end{array}$ & $\begin{array}{l}40,92 \pm 0,64^{\mathrm{aA}} \\
38,79 \pm 3,31^{\mathrm{bB}}\end{array}$ & $\begin{array}{l}41,28 \pm 0,26^{\mathrm{aA}} \\
39,71 \pm 1,55^{\mathrm{bB}}\end{array}$ \\
\hline & \multicolumn{3}{|c|}{$\begin{array}{l}\text { Idade } \\
\text { Age }\end{array}$} \\
\hline $\begin{array}{l}\text { Temperatura ambiental } \\
\text { Environmental temperature }\end{array}$ & $\begin{array}{l}14 \text { dias } \\
\text { days }\end{array}$ & $\begin{array}{l}28 \text { dias } \\
\text { days }\end{array}$ & $\begin{array}{l}45 \text { dias } \\
\text { days }\end{array}$ \\
\hline $\begin{array}{l}\text { Termoneutra }\left(25^{\circ} \mathrm{C}\right) \\
\text { Thermo-neutral } \\
\text { Fria }\left(16^{\circ} \mathrm{C}\right) \\
\text { Cold }\end{array}$ & $\begin{array}{l}41,34 \pm 0,19^{\mathrm{aA}} \\
41,13 \pm 0,39^{\mathrm{aA}}\end{array}$ & $\begin{array}{l}41,05 \pm 0,77^{\mathrm{aA}} \\
38,66 \pm 3,18^{\mathrm{cB}}\end{array}$ & $\begin{array}{l}41,15 \pm 0,29^{\mathrm{aA}} \\
39,84 \pm 1,67^{\mathrm{bB}}\end{array}$ \\
\hline
\end{tabular}

frias $\left(16^{\circ} \mathrm{C}\right)$ e por longo períodos, isto é, por 28 e 45 dias. $\mathrm{O}$ fato de que aos 14 dias de idade a temperatura corporal das aves Hubbard criadas no frio foi semelhante à de suas paralelas colocadas em termoneutralidade e das aves caipiras de pescoço pelado sugere que houve uma capacidade homeostática dessas aves na regulação da temperatura, mas ela foi curta e transiente. Efetivamente, o estresse pelo frio foi iniciado quando as aves tinham 10 dias de idade e, quando essa situação se prolongou, a capacidade homeotérmica das aves Hubbard foi prejudicada, conforme demonstraram os resultados de temperatura corporal dessas aves aos 28 e 45 dias de idade. Esses resultados indicaram que os frangos de pescoço pelado são homeotérmicos mais competentes do que aqueles selecionados para alta produtividade, como as aves da linhagem Hubbard. Entretanto, se o período de estresse pelo frio não for prolongado, por mais de 3 ou 4 dias, as aves Hubbard podem manter a temperatura corporal dentro de limites normais.

R. Bras. Zootec., v.31, n.3, p.1442-1450, 2002 (suplemento)
O custo produtivo da manutenção da temperatura corporal dentro de limites que permitam a sobrevivência das aves foi sentido tanto para os frangos de pescoço pelado como para aqueles da linhagem Hubbard. De fato, a atividade metabólica é dirigida prioritariamente para a manutenção da vida e, depois, para a produção (Macari et al. 1994). Nas aves de pescoço pelado, o prejuízo produtivo foi menor e somente a conversão alimentar foi afetada. Todavia, para as aves Hubbard, todas as variáveis analisadas, ganho de peso, conversão alimentar e taxa de mortalidade foram expressivamente prejudicadas. Isto significa que, para as aves Hubbard, o estresse pelo frio foi assinalado de maneira muito mais intensa do que para as de pescoço pelado.

Quantidade de Hsp70 no músculo cardíaco

Os resultados estatísticos mostraram que não houve efeito $(\mathrm{P}>0,05)$ da linhagem ou da temperatura de criação sobre os níveis de Hsp70 medidos no músculo cardíaco. Em média, no coração dos frangos caipiras foi detectado $14,46 \pm 2,87 \mathrm{ng} / \mathrm{m}$ de Hsp 
contra $14,50 \pm 2,43 \mathrm{ng} / \mathrm{m}$ das aves Hubbard. Em temperatura de criação termoneutra e fria, os níveis

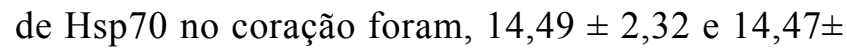
$2,54 \mathrm{ng} / \mathrm{m}$, respectivamente.

No entanto, a análise estatística revelou que houve efeito $(\mathrm{P}<0,05)$ da idade das aves e da interação idade $\mathrm{x}$ linhagem. Na Tabela 3 pode-se observar que as aves Hubbard apresentaram um nível de Hsp70 no coração significativamente menor aos 28 e 45 dias, em relação aos 14 dias. Já, para as aves caipiras não se observaram alterações significativas nos níveis do tecido do coração de Hsp70.

\section{Quantidade de Hsp70 no pulmão}

Os fatores linhagem, idade e a interação idade $\mathrm{x}$ temperatura de criação afetaram significativamente $(\mathrm{P}<0,05)$ os níveis de Hsp70 no pulmão das aves. Como observado na Tabela 4 , as aves da linhagem Hubbard apresentaram uma menor quantidade de Hsp70 no pulmão do que a aves caipiras, independente da temperatura de criação. Considerando-se a idade de criação das aves e a temperatura de criação, independente da linhagem, em condições termoneutras, mas não no frio, o nível de Hsp70 no pulmão das aves aos 45 dias de idade foi menor do que aos 14 e 28 dias. Aos 14 dias de idade das aves, no entanto, a quantidade de Hsp70 no pulmão das aves submetidas ao frio era menor do que naquelas mantidas sob termoneutralidade ambiental.

Os resultados produtivos, de mortalidade e de capacidade de homeotermia das aves obtidos neste experimento confirmam a importância da interação genótipo vs ambiente e indicam que os estudos futuros deveriam enfatizar a procura de soluções genéticas para a resolução de problemas de produtividade dos frangos de corte induzidos pelo ambiente, conforme mencionado por Ledur (2001). Entre eles, podese mencionar a capacidade genética que as aves têm em sintetizar pequenas proteínas para a proteção celular contra as agressões do meio ambiente, como as Hsps.

Dentre os fatores que poderiam induzir o aumento da síntese das Hsps, uma delas a Hsp70, estão a temperatura (frio, calor) e a anóxia tecidual (Morimoto et al., 1994). Neste estudo, o frio do ambiente a que as aves foram submetidas foi assinalado como um estresse, no aspecto de resposta produtiva para ambas as linhagens, e na incidência de mortes por SA nos frangos da linhagem Hubbard, em conseqüência da anóxia tecidual. Entretanto, não se observou aumento de síntese de Hsp70 devido ao frio, e/ou à possível hipóxia celular, nos tecidos do coração e pulmão de ambas as linhagens estudas.

Várias hipóteses podem ser levantadas com relação à ausência de efeito do frio sobre a indução da síntese de Hsp70 nos tecidos. A primeira delas, e a mais óbvia, é de que a temperatura de criação não induz a um aumento de síntese de Hsp70, contrariando pesquisas anteriores (Morimoto et al., 1994). Mas, porque o fator estressante tem que determinar uma resposta sistêmica intensa para que ocorra a síntese de Hsp, como por exemplo alterações para mais de $2,5^{\circ} \mathrm{C}$ da temperatura corporal de aves submetidas a estresse por calor (Guerreiro, 1999), o resultado obtido pode significar que o estresse pelo frio aplicado neste experimento não foi suficiente para haver a indução de maior síntese de Hsp70. Nessa hipótese, como a temperatura corporal das aves Hubbard submetidas ao frio foi $2,6^{\circ} \mathrm{C}$ menor do que as das suas

Tabela 3 - Comparação de médias dos níveis de Hsp70 (ng/mg de proteína total) dentro da interação idade $X$ linhagem, para as amostras de coração

Table 3 - Average levels of Hsp70 comparison ( $\mathrm{ng} / \mathrm{mg}$ of total protein) within age $X$ broiler interaction, for heart samples

\begin{tabular}{|c|c|c|c|}
\hline \multirow{3}{*}{$\begin{array}{l}\text { Linhagem } \\
\text { Strain }\end{array}$} & \multicolumn{3}{|c|}{$\begin{array}{c}\text { Idade }^{1} \\
\text { Age }^{1}\end{array}$} \\
\hline & 14 dias & 28 dias & 45 dias \\
\hline & Age & Age & Age \\
\hline Pescoço pelado & $15,22 \pm 3,80^{\mathrm{aA}}$ & $14,84 \pm 2,30^{\mathrm{aA}}$ & $13,33 \pm 2,51^{\mathrm{aA}}$ \\
\hline Naked neck & & & \\
\hline Hubbard & $16,90 \pm 2,66^{\mathrm{aA}}$ & $13,30 \pm 1,79^{\mathrm{bA}}$ & $13,31 \pm 2,84^{\mathrm{bA}}$ \\
\hline
\end{tabular}

\section{R. Bras. Zootec., v.31, n.3, p.1442-1450, 2002 (suplemento)}


Tabela 4 - Comparação de médias dos níveis de Hsp70 (ng/mg de proteína total) dentro de linhagens e dentro da interação idade $X$ temperatura, para as amostras de pulmão

Table 4 - Average levels of Hsp70 comparison ( $g / \mathrm{mg}$ of total protein) within broiler and age X temperature interaction, for lung samples

\begin{tabular}{|c|c|c|c|}
\hline $\begin{array}{l}\text { Linhagem } \\
\text { Strain } \\
\end{array}$ & \multicolumn{3}{|c|}{$\begin{array}{c}\mathrm{Hsp} 70(\mathrm{ng} / \mathrm{mg} \text { de proteína total })^{1} \\
\text { (ng/mg of total protein) }\end{array}$} \\
\hline Pescoço pelado & \multicolumn{3}{|c|}{$14,20 \pm 3,13^{\mathrm{A}}$} \\
\hline Naked neck & \multirow{2}{*}{\multicolumn{3}{|c|}{$12,50 \pm 2,66^{\mathrm{B}}$}} \\
\hline Hubbard & & & \\
\hline & \multicolumn{3}{|c|}{$\begin{array}{l}\text { Idade } \\
\text { Age }\end{array}$} \\
\hline $\begin{array}{l}\text { Temp. ambiental } \\
\text { Environmental temperature }\end{array}$ & $\begin{array}{l}14 \text { dias } \\
\text { days }\end{array}$ & $\begin{array}{l}28 \text { dias } \\
\text { days }\end{array}$ & $\begin{array}{l}45 \text { dias } \\
\text { days }\end{array}$ \\
\hline Termoneutro $\left(25^{\circ} \mathrm{C}\right)$ & $15,04 \pm 2,71^{\mathrm{aA}}$ & $14,47 \pm 2,02^{\mathrm{aA}}$ & $11,45 \pm 2,48^{\mathrm{bA}}$ \\
\hline $\begin{array}{l}\text { Thermo-neutral } \\
\text { Frio }\left(16^{\circ} \mathrm{C}\right) \\
\text { Cold }\end{array}$ & $12,12 \pm 2,71^{\mathrm{aB}}$ & $14,72 \pm 3,06^{\mathrm{aA}}$ & $12,29 \pm 3,18^{\mathrm{aA}}$ \\
\hline
\end{tabular}

irmãs criadas em termoneutralidade, presume-se que o efeito de uma mesma variação de temperatura corporal provocada por estresse de calor e frio tenha significados diferentes na síntese de Hsp celular. Aparentemente, a temperatura fria é um agente que provoca uma indução menor de Hsp70 do que a quente, corroborando com os resultados obtidos por Gividiez et al. (1999).

Ao contrário do aumento da síntese, o que se observou foi um declínio do nível de Hsp70 no músculo cardíaco das aves Hubbard. Isso não ocorreu para as aves de pescoço pelado, nas quais o nível de Hsp70 se manteve constante com a idade. A intensa injúria do tecido cardíaco das aves suscetíveis a SA, indicado pelo índice de hipertrofia cardíaca, que é maior com o avançar da idade (Gonzales et al., 1998a,b), poderia ser o fator determinante do menor nível de Hsp70, já que a estrutura celular muito comprometida poderia não responder à indução da síntese da proteína.

Emrelaçãoaos tecidosdopulmão, independentemente da linhagem estudada, enquanto em termoneutralidade o nível de Hsp70 caiu gradativamente, sob frio o nível foi oscilante, menor no início do estresse (14 dias) e maior aos 28 e 45 dias, em relação aos níveis das aves mantidas em termoneutralidade. $\mathrm{O}$ estudo também revelou que, independente da linhagem e da idade de criação, as aves de pescoço pelado tinham maior nível de Hsp70 no pulmão. Estes dados sugerem que são diferentes as respostas de indução de síntese de Hsp70 nos tecidos do coração e pulmão das aves resistentes e suscetíveis a SA. Vários estudos já confirmaram que existe uma certa especificidade de reação de indução de síntese de Hsp70 em função do tecido atingido, do tipo e de intensidade de estresse (Morimoto et al., 1994, Flanagan et al., 1995).

\section{Conclusões}

Verificou-se neste estudo que, em relação aos frangos Hubbard selecionados para alta produtividade, as aves caipiras de pescoço pelado são homeotérmicas mais competentes, resistentes à SA e apresentam maior indução de Hsp70 nos órgãos primariamente afetados por essa patogenia. Entretanto, é necessária a realização de novos estudos para a constatação da possível correlação entre níveis de Hs70 e maior ou menor suscetibilidade à SA.

\section{Literatura Citada}

FLANAGAN, S.W.; RYAN, A.J.; GISOLFI, C.V. et al. Tissuespecific Hsp70 response in animals undergoing heat stress. American Journal of Physiology, v.268, p.R28-R32, 1995. GIVISIEZ, P.E.N. Mecanismos moleculares e hormonais da termotolerância em frangos de corte. Jaboticabal: Universidade Estadual de São Paulo, 1997. 78p. Dissertação (Mestrado em Zootecnia) - Universidade Estadual de São Paulo, 1997.

GIVISIEZ, P.E.N.; FERRO, J.A.; FERRO, M.I.T. et al. Hepatic concentration of heat shock protein $70 \mathrm{kD}(\mathrm{Hsp} 70)$ in 
broilers subjected to different thermal treatments. British Poultry Science, v.40, p.292-296, 1999.

GONZALES, E.; BUYSE, J.; LODDI, M.M. et al. Performance, incidence of metabolic disturbances and endocrine variables of food-restricted male broiler chickens. British Poultry Science, v.39, p.671-678, 1998a.

GONZALES, E.; BUYSE, J.; TAKITA, T.S. et al. Metabolic disturbances in male broilers of different strains. 1. Performance, mortality and right ventricular hypertrophy. Poultry Science, v.77, p.1646-1653, 1998b.

GUERREIRO, E.M. Níveis da proteína de choque térmico Hsp70 em fígado e cérebro de frangos de corte aclimatados ao calor e submetidos a estresse calórico gradativo. Ribeirão Preto: Universidade de São Paulo, 1999. 83p. Dissertação (Mestrado em bioquímica) - Universidade de São Paulo, 1999.

GUERRIERO Jr., V.; RAYNES, D.A. Synthesis of heat stress proteins in lymphocytes from livestock. Journal of Animal Science, v.68, n.9, p.2779-83, 1990.

HARTREE, E.F. Determination of protein: A modification of the Lowry method that gives a linear photometric response. Analyses of Biochemistry, v.48, p.422-427, 1972.

JULIAN, R. J. The effect of increased sodium in the drinking water on right ventricular hypertrophy, right ventricular failure and ascites in broiler chickens. Avian Pathology, v.16, p.61-71, 1987.

JULIAN, R.J. Physiological, management and environmental triggers of the ascites sindrome: a review. Avian Pathology, v.29, p.519-527, 2000.

LAEMMLI, U.K. Cleavage of structural proteins during the assembly of head of bacteriophage T4. Nature, v.227,p.680$685,1970$.

LEDUR, M.C. Genótipo x ambiente. Avicultura Industrial, v.91, n.1087, p.14-24, 2001.

MACARI, M.; FURLAN, R.L.; GONZALES, E. Fisiologia aplicada a frangos de corte. Jaboticabal: Fundação Universidade Estadual Paulista, 1994. 296p.

MATSUDAIRA, P. Sequence from picomole quantities of proteins electroblotted onto polyvinylidene difluoride membranes. Journal of Biological Chemistry, v.262, n.21, p.10.035-10.038, 1987.
MAZZI. C.M. Análise da expressão da proteína de estresse em frangos de corte portadores do gene "Naked neck" (Pescoço Pelado) submetidos a estresse térmico gradativo. Jaboticabal: Universidade Estadual Paulista, 1998. 60p. Dissertação (Mestrado em Zootecnia) - Universidade Estadual Paulista, 1998.

MORIMOTO, R.I.; TISSIÈRES, A.; GEORGOPOULOS, C. Progress and perspectives on the biology of heat shock proteins and molecular chaperones. In:__ The biology of heat shock proteins and molecular chaperones. Cold Spring Harbor, p.1-30, 1994.

MORRISSEY, D.H. Silver strain for proteins in polyacrilamide gels: a modified procedure with enhanced uniform senitivity. Analyses Biochemistry., v.177, n.2, p.307-310, 1981.

NATIONAL RESEARCH COUNCIL - NRC. Nutrient requirements of poultry. 9.ed. Washington, D.C.: National Academy Press, 1994. 155p.

SAS INSTITUTE. User Guide: Statistics. versão 6, v.2. 4.ed. Cary: 1987.

TOWBIN, H.; STAEHELIN, T.; GORDON, J. Eletrophoretic transfer of proteins from polyacrylamide gels to nitrocellulose sheets: procedure and some applications. Biochemistry Journal, v.76, n.9, p.4350-4, 1979.

WIDEMAN, R.F.; TACKETT, C.D. Cardio-pulmonary function in broilers reared at warm or cool temperatures: effect of acute inhalation of $100 \%$ oxygen. Poultry Science, v.79, n.2, p.257-264, 2000.

YAHAV, S.; LUGER, D.; CAHANER, A. et al. Thermoregulation in naked neck chickens subjected to different ambient temperatures. British Poultry Science, v.39, p.133-138, 1998. 